\title{
The value of color Doppler ultrasound in the diagnosis of thyroid nodules: a systematic review and meta-analysis
}

\author{
Danbo Zhao ${ }^{1}$, Yi Jing ${ }^{1}$, Xiaoyi Lin $^{2}$, Bixia Zhang ${ }^{1}$ \\ ${ }^{1}$ Ultrasonic Image Center, The First People's Hospital of Wenling, Wenling, China; ${ }^{2}$ Ultrasonography Lab, Taizhou Central Hospital (Taizhou \\ University Hospital), Taizhou, China \\ Contributions: (I) Conception and design: D Zhao, B Zhang; (II) Administrative support: Y Jing; (III) Provision of study materials or patients: D Zhao, \\ Y Jing, X Lin; (IV) Collection and assembly of data: All authors; (V) Data analysis and interpretation: D Zhao, B Zhang; (VI) Manuscript writing: All \\ authors; (VII) Final approval of manuscript: All authors. \\ Correspondence to: Bixia Zhang. No. 333 Chuanan'an Road, Chengxi Street, Wenling, China. Email: ZBX20121226@163.com.
}

\begin{abstract}
Background: This study aimed to analyze the value of color Doppler ultrasound in the diagnosis of thyroid nodules.

Methods: We searched the PubMed, Web of Science, Embase, and Cochrane Library databases for randomized controlled trials (RCTs) on using color Doppler ultrasound, thyroid nodules, thyroid tumors, and Doppler ultrasound to diagnose the thyroid nodules. The outcome indicators in the articles had to include the numbers of true positives (TP), false positives (FP), false negatives (FN), and true negatives (TN). Subsequently, the Jadad tool was adopted to evaluate the quality of the included articles, and Review Manager 5.3 software was used to conduct a meta-analysis of the experimental data.
\end{abstract}

Results: A total of eight suitable articles were selected. The results showed that the estimated sensitivity and specificity of color Doppler ultrasound for the diagnostic of thyroid nodules were 0.46-0.89 and 0.001.00, respectively. The pooled estimate of sensitivity for the different articles was 0.71 [95\% confidence interval (CI): 0.46-0.89], and the pooled estimate of specificity was 0.77 (95\% CI: 0.00-1.00). The area under the summary receiver operating characteristic (SROC) curve (AUC) was 0.917 , which was larger than 0.9 , signifying high diagnostic accuracy. This suggests that color doppler ultrasound can realize the clinical diagnosis of thyroid nodules.

Discussion: In summary, the results of this study could provide a clinical data for the promotion and application of color Doppler ultrasound in the clinical diagnosis of thyroid nodules, as well as further reliable data for follow-up clinical research on the diagnosis and treatment of thyroid nodules.

Keywords: Color Doppler ultrasound; thyroid nodules; diagnosis value; meta-analysis

Submitted Oct 30, 2021. Accepted for publication Dec 10, 2021.

doi: $10.21037 /$ gs-21-752

View this article at: https://dx.doi.org/10.21037/gs-21-752

\section{Introduction}

The thyroid is one of the most important endocrine organs in the human body (1), and is also a key gland for all vertebrates. Clinically, thyroid nodules are the most common type of thyroid disease (2). A thyroid nodule is a mass that exists in the thyroid gland and moves up and down with the swallowing action of the human body. There are generally many pathogenic factors, and the etiology is more complicated. The types of diseases that will appear in clinical thyroid nodules are also diverse; for example, thyroid degeneration, inflammation, autoimmunity, and new organisms can all appear as nodules $(3,4)$. Thyroid nodules can be single or multiple. Multiple nodules have a higher incidence than single nodules, but single nodules account for a larger proportion of thyroid cancers. In recent years, relevant literature has gathered general statistics 
on the incidence of thyroid disease in China, which has been increasing every year. According to relevant statistics, approximately $5 \%$ of people may have thyroid nodules in their bodies, and the inaccessible thyroid nodules diagnosed during ultrasound examination are as high as $50 \%$. However, more than $80 \%$ of the nodules found in clinical practice are confirmed as benign nodules or nodules with no other functions (5-7), and generally do not require special medical treatment. Thyroid nodules generally include benign nodules, toxic nodular goiter, simple nodular goiter, strange lymphatic thyroiditis, subacute thyroiditis, and other diseases. They are more common with benign swelling and pain, and manifest clinically as neck lumps, neck swelling, and suffocation. There is a sense of congestion in the pharynx, or accompanied by palpitation, upset, irritability, and hyperhidrosis; a small number of neck pains can also be seen, and the voice is clear and dumb $(8,9)$.

A small number of people have a rapid increase in local thyroid masses, accompanied by pain. Also, for a small number of patients with hyperthyroidism, palpitations, hyperhidrosis, hand tremor, and weight loss are the main clinical manifestations; or it may manifest as cold, fatigue, and edema due to combination with hypothyroidism. When it is combined with acute or subacute thyroiditis, there may be obvious pain and tenderness in the thyroid and surrounding areas. When the nodules compress the surrounding tissues, corresponding clinical manifestations such as hoarseness, suffocation, and dysphagia may appear $(10,11)$.

There will also be some high-functioning adenomas or malignant nodules in the clinic. For these malignant nodules, medical intervention and surgical resection are required. Among them, thyroid cancer caused by malignant nodules is extremely harmful, difficult to treat, has a poor prognosis, and places considerable pressure on the physiology and psychology of patients. Therefore, the diagnosis of thyroid nodules is extremely important. Effective diagnosis when nodules appear can improve the survival and quality of life of patients.

At present, the clinical diagnosis of thyroid nodules is mainly divided into three categories, namely manual palpation, imaging examination, and histological examination. Palpation is generally only used as a preliminary examination, while the specific diagnosis uses imaging examination and fine-needle aspiration biopsy (FNAB). The diagnostic accuracy of FNAB is as high as $90 \%$, but it is often not accepted by patients because it can cause wounds and injuries (12). Imaging examinations include computed tomography (CT), Doppler ultrasound, and magnetic resonance imaging (MRI) (13). Studies have shown that the diagnostic efficiency of color Doppler ultrasound for thyroid nodules is as high as $80.9 \%$ (14).

Regardless of the method of diagnosis, the key lies in clarifying the etiological classification of thyroid nodules, determining their nature, and distinguishing benign and malignant nodules in order to determine the treatment plan. Therefore, attention should be paid to the diagnosis of the causes and the differentiation between benign and malignant when thyroid nodules are diagnosed. Based on this, this article retrieved and included literature to conduct a systematic evaluation of color Doppler ultrasound imaging for the diagnosis of thyroid nodules, and compare its accuracy and efficiency for thyroid nodules, thus providing a reference for improving the efficiency of early diagnosis of thyroid nodules. We present the following article in accordance with the PRISMA reporting checklist (available at https://dx.doi.org/10.21037/gs-21-752).

\section{Methods}

\section{Literature retrieval}

We searched for relevant articles on databases such as PubMed, Web of Science, Embase, and The Cochrane Library, and the search time ranged from January 2000 to September 2020. The search terms included "color Doppler ultrasound", "thyroid nodule", "thyroid tumor", and "diagnostic value of Doppler ultrasound".

\section{Literature inclusion and exclusion criteria}

Studies meeting the following criteria was eligible for inclusion in this study: (I) published articles analyzing the diagnostic value of color Doppler ultrasound for thyroid nodules; (II) studies that directly or indirectly evaluated indicators of the diagnostic effect of thyroid nodules; and (III) articles that included a sample size of at least 15 cases.

Studies were excluded based on the following criteria: (I) articles that included repeated data; (II) reviews, conference reports, empirical lectures, and case reports; (III) unrelated articles; (IV) studies without a research control group, or where the samples between groups were not comparable; and $(\mathrm{V})$ articles without clear reporting of the outcome indicators and those without complete data. 
Table 1 Risk bias assessment of the included articles

\begin{tabular}{lccccccccccccccc}
\hline First author & Year of publication & 1 & 2 & 3 & 4 & 5 & 6 & 7 & 8 & 9 & 10 & 11 & 12 & 14 \\
\hline Lin & 2009 & $\mathrm{Y}$ & $\mathrm{Y}$ & $\mathrm{Y}$ & $\mathrm{U}$ & $\mathrm{Y}$ & $\mathrm{Y}$ & $\mathrm{Y}$ & $\mathrm{Y}$ & $\mathrm{Y}$ & $\mathrm{Y}$ & $\mathrm{U}$ & $\mathrm{Y}$ & $\mathrm{Y}$ & $\mathrm{Y}$ \\
Gul & 2009 & $\mathrm{Y}$ & $\mathrm{Y}$ & $\mathrm{Y}$ & $\mathrm{U}$ & $\mathrm{Y}$ & $\mathrm{Y}$ & $\mathrm{Y}$ & $\mathrm{Y}$ & $\mathrm{Y}$ & $\mathrm{Y}$ & $\mathrm{U}$ & $\mathrm{Y}$ & $\mathrm{Y}$ & $\mathrm{Y}$ \\
Gannon & 2018 & $\mathrm{Y}$ & $\mathrm{Y}$ & $\mathrm{Y}$ & $\mathrm{U}$ & $\mathrm{Y}$ & $\mathrm{Y}$ & $\mathrm{Y}$ & $\mathrm{Y}$ & $\mathrm{Y}$ & $\mathrm{U}$ & $\mathrm{U}$ & $\mathrm{Y}$ & $\mathrm{Y}$ & $\mathrm{Y}$ \\
Bozbora & 2002 & $\mathrm{Y}$ & $\mathrm{Y}$ & $\mathrm{Y}$ & $\mathrm{U}$ & $\mathrm{Y}$ & $\mathrm{Y}$ & $\mathrm{Y}$ & $\mathrm{Y}$ & $\mathrm{Y}$ & $\mathrm{Y}$ & $\mathrm{U}$ & $\mathrm{Y}$ & $\mathrm{Y}$ & $\mathrm{Y}$ \\
Li & 2016 & $\mathrm{Y}$ & $\mathrm{Y}$ & $\mathrm{Y}$ & $\mathrm{U}$ & $\mathrm{Y}$ & $\mathrm{Y}$ & $\mathrm{Y}$ & $\mathrm{Y}$ & $\mathrm{Y}$ & $\mathrm{Y}$ & $\mathrm{U}$ & $\mathrm{Y}$ & $\mathrm{Y}$ & $\mathrm{Y}$ \\
Stacul & 2007 & $\mathrm{Y}$ & $\mathrm{Y}$ & $\mathrm{Y}$ & $\mathrm{U}$ & $\mathrm{Y}$ & $\mathrm{Y}$ & $\mathrm{Y}$ & $\mathrm{Y}$ & $\mathrm{Y}$ & $\mathrm{U}$ & $\mathrm{U}$ & $\mathrm{Y}$ & $\mathrm{Y}$ & $\mathrm{Y}$ \\
Palaniappan & 2016 & $\mathrm{Y}$ & $\mathrm{Y}$ & $\mathrm{Y}$ & $\mathrm{U}$ & $\mathrm{Y}$ & $\mathrm{Y}$ & $\mathrm{Y}$ & $\mathrm{Y}$ & $\mathrm{Y}$ & $\mathrm{Y}$ & $\mathrm{U}$ & $\mathrm{Y}$ & $\mathrm{Y}$ & $\mathrm{Y}$ \\
Ma & 2014 & $\mathrm{Y}$ & $\mathrm{Y}$ & $\mathrm{Y}$ & $\mathrm{U}$ & $\mathrm{Y}$ & $\mathrm{Y}$ & $\mathrm{Y}$ & $\mathrm{Y}$ & $\mathrm{Y}$ & $\mathrm{Y}$ & $\mathrm{U}$ & $\mathrm{Y}$ & $\mathrm{Y}$ & $\mathrm{Y}$ \\
\hline
\end{tabular}

1-14 were the item standards of QUADAS, and "Y" and "U" represented "Yes" and "Unclear", respectively. QUADAS, Quality Assessment of Diagnostic Accuracy Studies.

\section{Quality assessment}

Two researchers were required to conduct independent reading of the retrieved articles, read the full texts, and extract the relevant information. Any disagreements or disputes were resolved through discussion or the assistance of a third researcher. The Jadad scale was used to evaluate the quality of the included articles in terms of the following aspects: whether the article was a randomized controlled trial (RCT); whether the randomization method used was appropriate; whether the article was a double-blind test; whether the double-blinding method adopted was appropriate; whether there were patients that were lost to follow-up or withdrew during the research process; whether the reason was explained; and whether the article adopted an intentional analysis method. One point was for "Yes" and 0 points were for "No", and the total score was 5 points. A total score of less than 2 was classified as a low-quality study, and a total score greater than 2 was classified as a high-quality study.

The Quality Assessment of Diagnostic Accuracy Studies (QUADAS) tool was used to evaluate the quality of each included article, and the results are shown in Table 1. It can be seen that the 11 articles included in the study all had a low risk of bias and met the subsequent analysis requirements.

\section{Data extraction}

We extracted the first author, publication year, research type, gold standard (surgical pathology detection), evaluation result, diagnosis result, and other data from the included articles. The diagnosis result had to include the numbers of true positives (TP), false positives (FP), false negatives $(\mathrm{FN})$, and true negatives $(\mathrm{TN})$.

\section{Statistical analysis}

RevMan 5.3 software provided by the Cochrane Collaboration was adopted for data statistics and analysis. Firstly, the results were tested for heterogeneity using a test level of $\alpha=0.05$. At the same time, the Peto method was used to analyze the heterogeneity of the articles. When $\mathrm{I}^{2}<50 \%$, it was considered that there was no heterogeneity in the articles, and then the fixed effects model (FEM) was used for meta-analysis; however, when $\mathrm{I}^{2}>50 \%$, the articles were considered to be heterogeneous, and the random effects model (REM) was adopted for meta-analysis. The results of measurement data (using the same unit of measurement) were expressed as the weighted mean difference (WMD); otherwise, they were expressed as the standard mean difference (SD). The results of count data were expressed in relative risk (RR). All results were expressed with a $95 \%$ confidence interval (CI). Publication bias was evaluated through the symmetry of the funnel chart and the concentration of the article to the center line. Sensitivity analysis was to change the inclusion criteria (especially the controversial studies), exclude low-quality studies, and use different statistical methods/models to analyze the same data, etc. For example, after excluding a low-quality study, re-estimate the combined effect size and compare it with the results of the meta-analysis before the exclusion, to explore the degree of influence of the research on the combined effect size and the robustness of the results. 


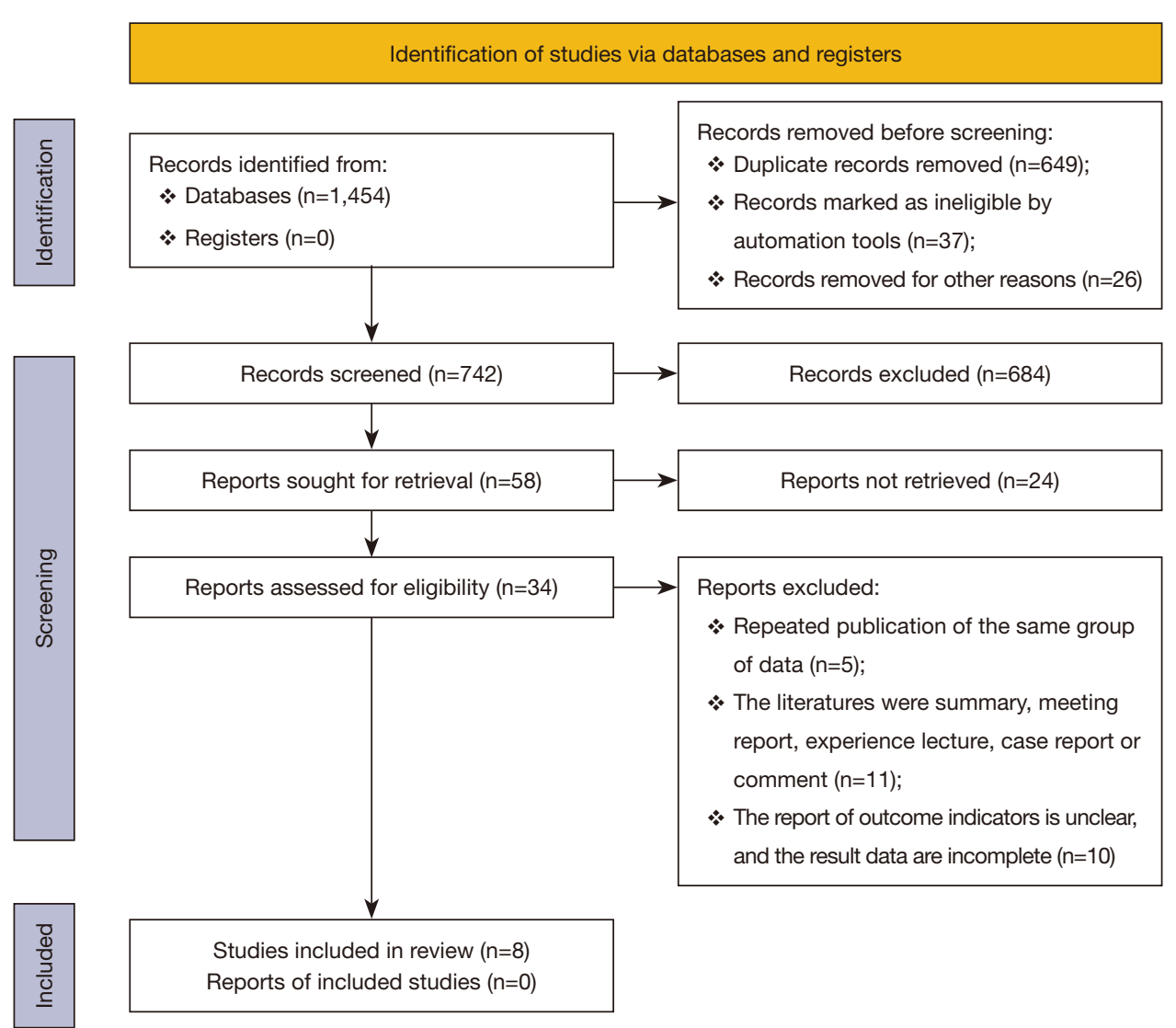

Figure 1 Literature retrieval process.

\section{Results}

\section{Literature retrieval and the basic characteristics of the included articles}

A total of 1,454 records were retrieved from the databases. After the duplicates were deleted, a total of 742 abstracts with certain relevance to this article were obtained. Two researchers read the abstracts and titles of these articles, and initially screened 58 articles that met the requirements. After further reading the full texts of these articles and excluding non-random, duplicate publications and unavailable literature, eight articles that met the requirements and were included in this study (15-22). The article retrieval process is shown in Figure 1, and the basic information of the included research articles was shown in Table 2.

\section{Risk bias assessment of the included articles}

Firstly, the bias risk assessment tool recommended by the
Cochrane System Review Manual was adopted to evaluate the quality of the included articles and the results are shown in Figures 2,3. None of the eight included articles had random sequence generation (selection bias), incomplete outcome data (selection bias), and selective reporting (reporting bias). On the whole, the risk of the articles included in this study was relatively low.

The Jadad scale was used to evaluate the quality of each included article, and the results are shown in Table 1. It can be seen that the eight articles included in this study all had a low risk of bias, which met the requirements of subsequent analysis.

\section{Meta-analysis on the diagnostic value of color Doppler ultrasound for thyroid nodules}

We evaluated the value of transcranial Doppler in the diagnosis of ischemic cerebrovascular disease, and the results are shown in Figure 4. It can be seen that the estimated sensitivity of color Doppler ultrasound technology for the 
Table 2 Basic characteristics of the included articles.

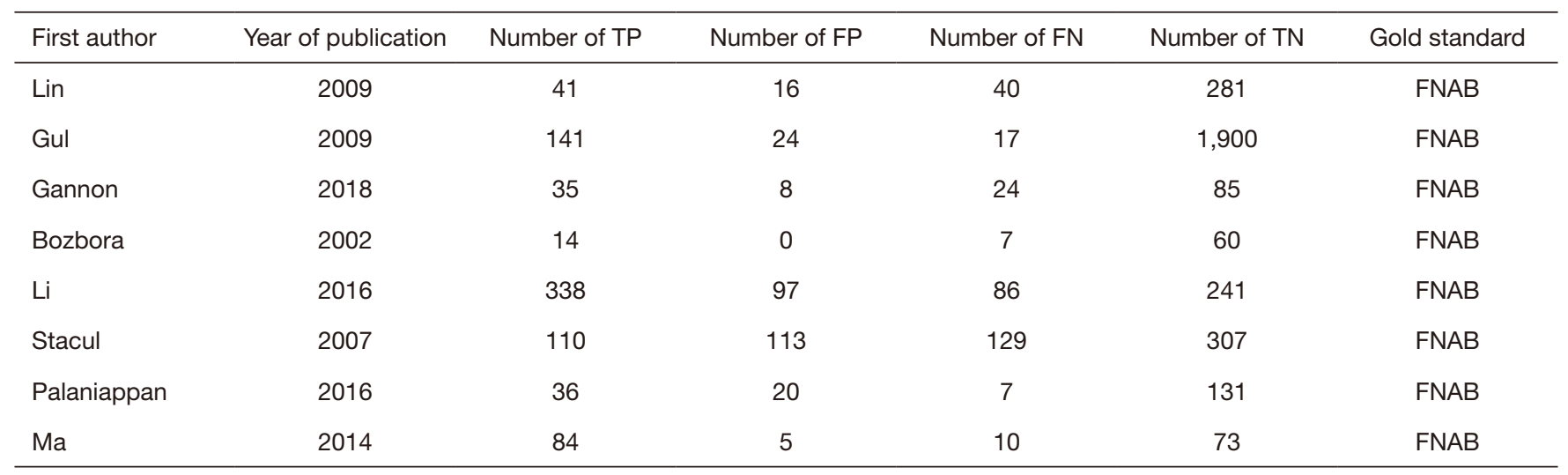

TP, true positives; FP, false positives; FN, false negatives; TN, true negatives; FNAB, fine-needle aspiration biopsy.

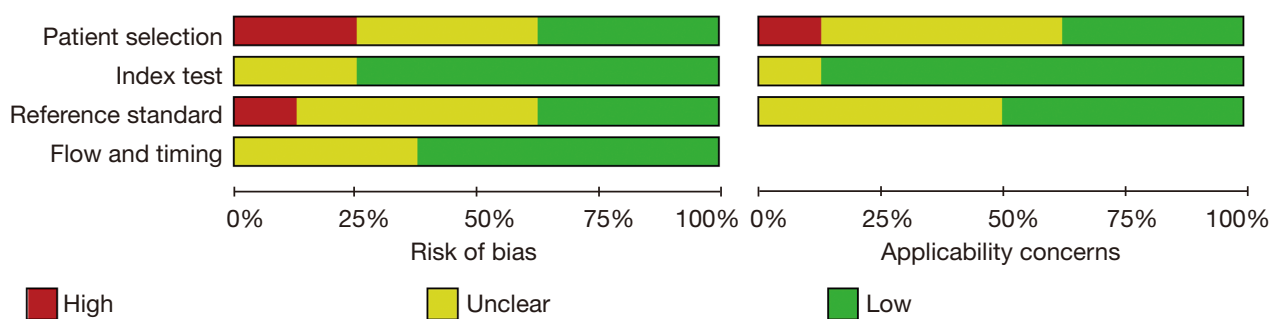

Figure 2 Assessment of risk bias of the included articles.

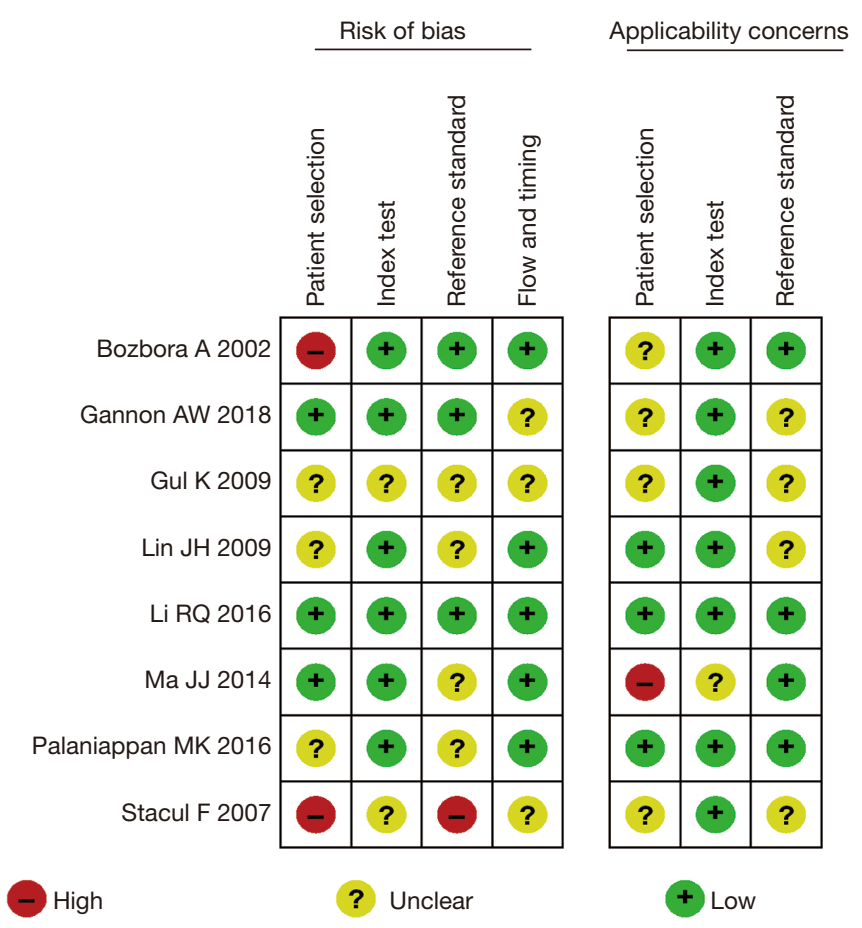

Figure 3 Multiple risk bias evaluation results of included articles. 


Study
Bozbora A 2002
Gannon AW 2018
Gul K 2009
Li RQ 2016
Lin JH 2009
Ma JJ 2014
Palaniappan MK 2016
Stacul F 2007

$\begin{array}{rrrr}\text { TP } & \text { FP } & \text { FN } & \text { TN } \\ 14 & 0 & 7 & 60 \\ 35 & 8 & 24 & 85 \\ 141 & 24 & 17 & 1900 \\ 338 & 97 & 86 & 241 \\ 41 & 16 & 40 & 281 \\ 84 & 5 & 10 & 0 \\ 36 & 20 & 7 & 131 \\ 110 & 113 & 129 & 307\end{array}$
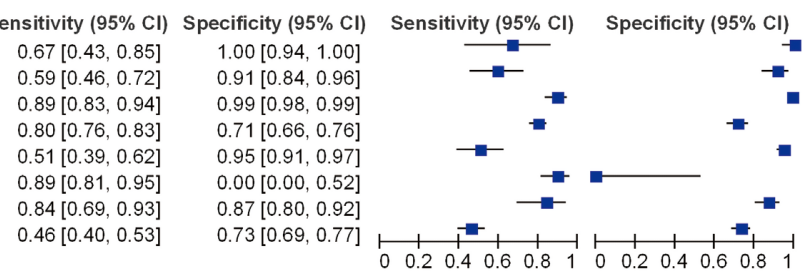

Figure 4 Forest map for the diagnostic value of color Doppler ultrasound in thyroid nodules. CI, confidence interval.

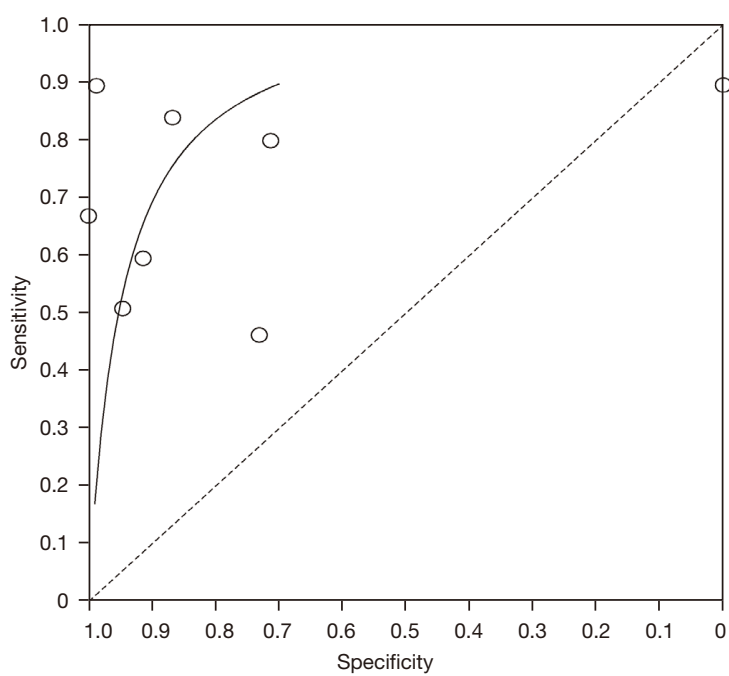

Figure 5 SROC for the diagnostic efficiency of transcranial Doppler for ischemic cerebrovascular disease. SROC, summary receiver operating characteristic; $\mathrm{CI}$, confidence interval.

diagnostic value of thyroid nodules was $0.46-0.89$, while the specificity of the diagnostic value was $0.00-1.00$. The value analysis of color Doppler ultrasound technology in diagnosing thyroid nodules using a bivariate model is shown in Figure 5. It can be seen that the pooled estimate of sensitivity of different studies was $0.71(0.46-0.89)$, and the specific pooled estimate was $0.77(0.00-1.00)$. The area under the summary receiver operating characteristic (SROC) curve (AUC) was 0.917.

\section{Analysis of publication bias}

The Deek funnel chart was drawn using STATA12.0 software (StataCorp, USA) to analyze the publication bias of the included studies, and the results are shown in Figure 6. It can be seen that the included articles were evenly distributed on both sides of the regression line, and the asymmetric test results showed that there was no obvious

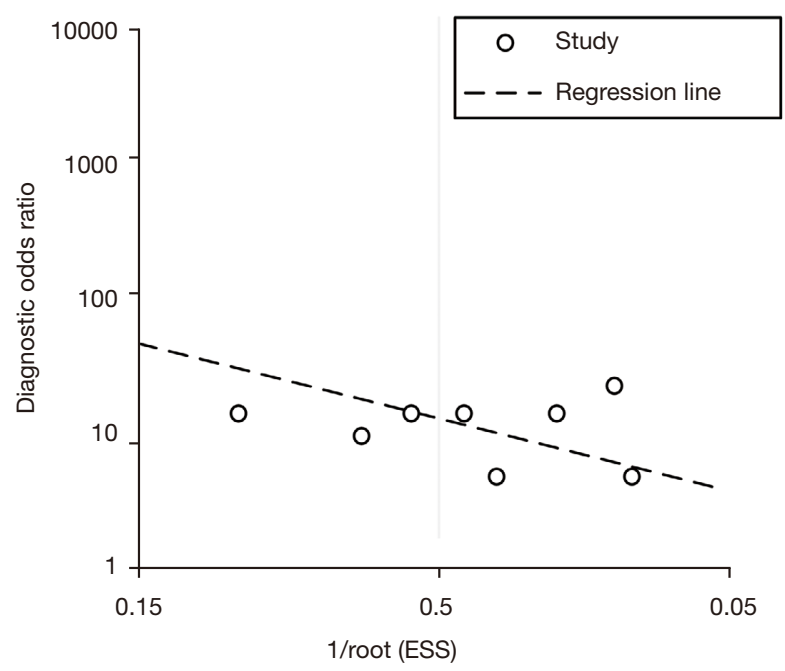

Figure 6 Deek's funnel chart of included articles. ESS, effective sample size.

publication bias $(\mathrm{P}=0.312)$.

\section{Discussion}

In recent years, with the popularization and development of comprehensive physical examinations, the incidence of thyroid nodules has been found to be gradually increasing in the physical examinations of the general population, but the specific reasons remain unclear. There are speculations in the relevant literature that it may be caused by increased pressure and excessive consumption of iodized salt due to the acceleration of social development, but there is no clinical data to support this. According to relevant epidemiological reports $(23,24)$, approximately 5 out of every 100 people suffer from asymptomatic thyroid nodules, and in women and elderly people, this probability is even higher. At present, there is no accurate diagnosis of these nodules, and no specific symptoms in clinical practice. This 
is because there is not much difference in the morphology of benign and malignant nodules. Therefore, diagnosing the nature of nodules from medical imaging remains a huge challenge. In addition to imaging diagnosis, clinical pathology can only be diagnosed by FNAB; however, this diagnostic method is an invasive operation, which is painful and risky for the patient. Therefore, finding an effective and reliable non-invasive diagnostic method for benign and malignant thyroid nodules has become a current research hotspot.

The significant clinical value of color Doppler ultrasound in the diagnosis of thyroid nodules has gradually attracted the attention of clinicians. In practical applications, the specificity and sensitivity of the ultrasound image for the diagnosis of malignant thyroid nodules are $0.39-1.00$ and $0.72-0.96$, respectively, after integrating the various indicators of color Doppler ultrasound. These results show that color Doppler ultrasound is crucial to improve the diagnostic efficiency of malignant thyroid nodules after integrating various ultrasound image indicators (25-27).

Color Doppler can also be applied to patients whose FNAB examination does not have a clear result, because FNAB for thyroid nodules has certain limitations. When it lacks a sufficient number of cells, the cytological examination in cystic or hemorrhagic lesions will have a certain chance of missed diagnosis. Ultrasound has considerable clinical value in separating cystic and solid lesions. Wienke et al. (28) reported that $60 \%$ of benign thyroid nodules are entities and $40 \%$ are cystic structures. However, these results contradict the findings of other researchers. Clinical experience has demonstrated that there are multiple cystic components. Generally speaking, there is a possibility that papillary cancer can be eliminated. For patients with certain risk factors for thyroid cancer, it is necessary to use rapid FNAB or biopsy to effectively identify benign cystic nodules. In addition, calcification can be detected from about $10-15 \%$ of thyroid nodules, but the location and pattern of calcification have a huge impact on the prognosis of benign and malignant tumors. Calcification may be the most reliable feature of benign nodules; when the calcification is large and rough, the nodules are more likely to be benign $(29,30)$, but when the calcification points are small and punctate, it is more likely to be a malignant tumor. Pathologically, these small calcifications may come from the sand body, usually seen in papillary carcinoma. Color Doppler can confirm the presence of calcification $(\mathrm{P}<0.05)$. Data in some studies $(31-33)$ indicates that microcalcification has high specificity $(95 \%)$ and low sensitivity (29-36\%) for malignant thyroid tumors.

In this study, meta-analysis was performed to systematically evaluate the value of color Doppler ultrasound in the diagnosis of thyroid nodules. The results showed that the sensitivity and specificity of color Doppler ultrasound in the diagnosis of thyroid nodules were 0.93 and 0.96, respectively, and the AUC was 0.917. These results suggest that the use of color Doppler ultrasound technology for the diagnosis of thyroid nodules has high sensitivity and specificity.

Ultrasonography has the advantages of non-invasive, non-radioactive, easy operation and reproducibility, so it can be used as the preferred method for thyroid diseases Compared with gray-scale ultrasound, color Doppler ultrasound imaging can display the blood flow signal in the lesion tissue in real time. Therefore, the clinical diagnosis efficiency of color Doppler ultrasound imaging is high, and it provides important information for the diagnosis and identification of thyroid diseases. However, due to the multi-source and coexistence of thyroid nodules, it is necessary to closely combine the clinical data of the patient to minimize the rate of misdiagnosis and missed diagnosis. When necessary, pathological biopsy can be performed under ultrasound guidance to confirm diagnosis and treatment.

\section{Conclusions}

This study aimed to analyze the diagnostic value of color Doppler ultrasound for thyroid nodules. A total of eight suitable included articles were selected. The Jadad tools were used to evaluate the quality of the included articles, and Review Manager 5.3 software was used to conduct a meta-analysis of the experimental data. According to the results of the meta-analysis, the sensitivity and specificity of color Doppler ultrasound technology for the diagnostic value of thyroid nodules were estimated to be $0.52-1.00$ and $0.78-1.00$, respectively. The pooled estimate of sensitivity of different articles was 0.93 (95\% CI: $0.75-1.00$ ), and the pooled estimate of specificity was 0.96 (95\% CI: $0.78-1.00$ ). Also, since the AUC in this study was greater than 0.9 (0.917), it can be considered that this method is highly accurate in the diagnosis of thyroid nodules.

However, this study only used computer retrieval methods to find relevant articles, and did not consider the effect evaluation of color Doppler ultrasound technology and other imaging techniques in the diagnosis of the disease. Subsequently, further include more articles, and 
the quality of the included articles would be controlled in accordance with the QUADAS standard. In summary, the results of this study can provide a theoretical basis for the promotion and application of color Doppler ultrasound technology in the clinical diagnosis of thyroid nodules, providing further reliable data for the follow-up clinical diagnosis and treatment of thyroid nodules.

\section{Acknowledgments}

Funding: None.

\section{Footnote}

Reporting Checklist: The authors have completed the PRISMA reporting checklist. Available at https://dx.doi. org/10.21037/gs-21-752

Conflicts of Interest: All authors have completed the ICMJE uniform disclosure form (available at https://dx.doi. org/10.21037/gs-21-752). The authors have no conflicts of interest to declare.

Ethical Statement: The authors are accountable for all aspects of the work in ensuring that questions related to the accuracy or integrity of any part of the work are appropriately investigated and resolved.

Open Access Statement: This is an Open Access article distributed in accordance with the Creative Commons Attribution-NonCommercial-NoDerivs 4.0 International License (CC BY-NC-ND 4.0), which permits the noncommercial replication and distribution of the article with the strict proviso that no changes or edits are made and the original work is properly cited (including links to both the formal publication through the relevant DOI and the license). See: https://creativecommons.org/licenses/by-nc-nd/4.0/.

\section{References}

1. Knezevic J, Starchl C, Tmava Berisha A, et al. ThyroidGut-Axis: How Does the Microbiota Influence Thyroid Function? Nutrients 2020;12:1769.

2. Winther KH, Rayman MP, Bonnema SJ, et al. Selenium in thyroid disorders - essential knowledge for clinicians. Nat Rev Endocrinol 2020;16:165-76.

3. Churilov LP, Sobolevskaia PA, Stroev YI. Thyroid gland and brain: Enigma of Hashimoto's encephalopathy. Best
Pract Res Clin Endocrinol Metab 2019;33:101364.

4. Shi YX, Chen L, Liu YC, et al. Differences among the Thyroid Imaging Reporting and Data System proposed by Korean, the American College of Radiology and the European Thyroid Association in the diagnostic performance of thyroid nodules. Transl Cancer Res 2020;9:4958-67.

5. Grani G, Sponziello M, Pecce V, et al. Contemporary Thyroid Nodule Evaluation and Management. J Clin Endocrinol Metab 2020;105:dgaa322.

6. Pemayun TG. Current Diagnosis and Management of Thyroid Nodules. Acta Med Indones 2016;48:247-57.

7. Perri F, Giordano A, Pisconti S, et al. Thyroid cancer management: from a suspicious nodule to targeted therapy. Anticancer Drugs 2018;29:483-90.

8. Bauer AJ. Thyroid nodules in children and adolescents. Curr Opin Endocrinol Diabetes Obes 2019;26:266-74.

9. Chen J, You H, Li K. A review of thyroid gland segmentation and thyroid nodule segmentation methods for medical ultrasound images. Comput Methods Programs Biomed 2020;185:105329.

10. Mattar SAM, Koh SJQ, Rama Chandran S, et al. Subacute thyroiditis associated with COVID-19. BMJ Case Rep 2020;13:237336.

11. Brancatella A, Ricci D, Viola N, et al. Subacute Thyroiditis After Sars-COV-2 Infection. J Clin Endocrinol Metab 2020;105:dgaa276.

12. Nguyen DT, Kang JK, Pham TD, et al. Ultrasound Image-Based Diagnosis of Malignant Thyroid Nodule Using Artificial Intelligence. Sensors (Basel) 2020;20:1822.

13. Wei X, Zhu J, Zhang H, et al. Visual Interpretability in Computer-Assisted Diagnosis of Thyroid Nodules Using Ultrasound Images. Med Sci Monit 2020;26:e927007.

14. Zhu YC, Zhang Y, Deng SH, et al. A Prospective Study to Compare Superb Microvascular Imaging with Grayscale Ultrasound and Color Doppler Flow Imaging of Vascular Distribution and Morphology in Thyroid Nodules. Med Sci Monit 2018;24:9223-31.

15. Lin JH, Chiang FY, Lee KW, et al. The role of neck ultrasonography in thyroid cancer. Am J Otolaryngol 2009;30:324-6.

16. Gul K, Ersoy R, Dirikoc A, et al. Ultrasonographic evaluation of thyroid nodules: comparison of ultrasonographic, cytological, and histopathological findings. Endocrine 2009;36:464-72.

17. Gannon AW, Langer JE, Bellah R, et al. Diagnostic Accuracy of Ultrasound With Color Flow Doppler in Children With Thyroid Nodules. J Clin Endocrinol 
Metab 2018;103:1958-65.

18. Bozbora A, Erbil Y, Ozarmagan S, et al. Color Doppler sonography in cold thyroid nodules for malignancy prediction. Acta Chir Belg 2002;102:259-62.

19. Li RQ, Yuan GH, Chen M, et al. Evaluation of Diagnostic Efficiency of Ultrasound Features on Malignant Thyroid Nodules in Chinese Patients. Chin Med J (Engl) 2016;129:1784-8.

20. Stacul F, Bertolotto M, De Gobbis F, et al. US, colourDoppler US and fine-needle aspiration biopsy in the diagnosis of thyroid nodules. Radiol Med 2007;112:751-62.

21. Palaniappan MK, Aiyappan SK, Ranga U. Role of Gray Scale, Color Doppler and Spectral Doppler in Differentiation Between Malignant and Benign Thyroid Nodules. J Clin Diagn Res 2016;10:TC01-6.

22. Ma JJ, Ding H, Xu BH, et al. Diagnostic performances of various gray-scale, color Doppler, and contrast-enhanced ultrasonography findings in predicting malignant thyroid nodules. Thyroid 2014;24:355-63.

23. Xu W, Chen Z, Liu H, et al. The association of thyroid nodule with non-iodized salt among Chinese children. PLoS One 2014;9:e102726.

24. Kalra B, Gupta Y, Kalra S. Preconception management of thyroid disorders. J Pak Med Assoc 2017;67:645-7.

25. Alexander LF, Patel NJ, Caserta MP, et al. Thyroid Ultrasound: Diffuse and Nodular Disease. Radiol Clin North Am 2020;58:1041-57.

26. Akkus Z, Cai J, Boonrod A, et al. A Survey of DeepLearning Applications in Ultrasound: Artificial Intelligence-Powered Ultrasound for Improving Clinical Workflow. J Am Coll Radiol 2019;16:1318-28.

Cite this article as: Zhao D, Jing Y, Lin X, Zhang B. The value of color Doppler ultrasound in the diagnosis of thyroid nodules: a systematic review and meta-analysis. Gland Surg 2021;10(12):3369-3377. doi: 10.21037/gs-21-752
27. Abbasian Ardakani A, Bitarafan-Rajabi A, Mohammadi A, et al. CAD system based on B-mode and color Doppler sonographic features may predict if a thyroid nodule is hot or cold. Eur Radiol 2019;29:4258-65.

28. Wienke JR, Chong WK, Fielding JR, et al. Sonographic features of benign thyroid nodules: interobserver reliability and overlap with malignancy. J Ultrasound Med 2003;22:1027-31.

29. Malhi HS, Velez E, Kazmierski B, et al. Peripheral Thyroid Nodule Calcifications on Sonography: Evaluation of Malignant Potential. AJR Am J Roentgenol 2019;213:672-5.

30. Gomes Ataide EJ, Ponugoti N, Illanes A, et al. Thyroid Nodule Classification for Physician Decision Support Using Machine Learning-Evaluated Geometric and Morphological Features. Sensors (Basel) 2020;20:6110.

31. Okasha HH, Mansor M, Sheriba N, et al. Role of elastography strain ratio and TIRADS score in predicting malignant thyroid nodule. Arch Endocrinol Metab 2021;64:735-42.

32. Al Nofal A, Gionfriddo MR, Javed A, et al. Accuracy of thyroid nodule sonography for the detection of thyroid cancer in children: systematic review and meta-analysis. Clin Endocrinol (Oxf) 2016;84:423-30.

33. Papapostolou KD, Evangelopoulou CC, Ioannidis IA, et al. Taller-than-wide Thyroid Nodules With Microcalcifications Are at High Risk of Malignancy. In Vivo 2020;34:2101-5.

(English Language Editor: A. Kassem) 